\title{
Toy Story: Childhood versus Children in Toy Museums
}

\author{
Anne Jodon Cole*, Eva Petersson Brooks**
}

\begin{abstract}
Toys are considered to be children's cultural objects, yet when placed in a toy museum context they become a collection for adult viewing. This article uses Kress and van Leeuwens' concept of 'semiotic landscape' wherein the exhibit provides a specific context of communication that becomes a mediating device between adults and children. The question then becomes, how does a display of static toys speak to a child's culture of play? Through interviews with toy museum curators and personal observations it was found that the exhibition was designed to have adults share and reflect stories about the toys with children. Such activity reflects a representation of toys as collections for adults (child's perspective) rather than the playthings of children (children's perspectives). Material culture of children was implicitly represented through playful, sensory, and affective engagement.
\end{abstract}

Key words: toy exhibits, material culture of children, semiotic landscape, play, narratives

When children pretend, they're using their imagination to move beyond the bounds of reality. A stick can be a magic wand. A sock can be a puppet. A small child can be a superhero. ${ }^{1}$-Fred Rogers, American Children's program TV host 1928-2003

\section{Introduction}

Mister Rogers, aka Fred Rogers, an American TV host for young children's television programs (1960s-2001) had it right: there are no boundaries in childrens' play. A simple item such as a stick can become something magical when a child has the opportunity for creative play. As the stick transforms, through a bit of hocus pocus, into a magical wand its meaning has shifted to one that holds significance for the child but not necessarily for an adult. Toys presented in toy museums seem to lose this magic by becoming static objects no longer capable of providing play. Toy museums are similar to other museums whose collections have been donated through estates or collectors with the sole purpose to preserve and present them to society. Museological research suggests that children are marginalized in a world directed by the voice of adults where the ideas of the child are often silenced (cf. Townsend, 2012; Roberts 2006; Hirschfeld 2002).

Thus, if the perspective is on childhood and not children, a sense of the joy and playfulness is missing. Lawrence Hirschfield reminds us, "children live and maintain cultural environments of their own. It is an environment where cultural reproduction takes place according to the constraints of adults' (2002:615). This situation raises four points of exploration regarding toy museums: 1) Who is the intended audience; 2) Who is involved in the process of representation/ presentation; 3) What social / historical narratives are presented, and 4) Whose voice is heard?

To answer these questions we draw on two case studies of Scandinavian toy museums (Den Gamle By, Arhus, DK and Leksaksmuseet, Stockholm, SE) with the aim to analyze the representation of the material culture of childhood (toys) through the analysis of the 'semiotic landscape' in parallel with semi-formal interviews of each curator: focus is placed on the signification produced by curators in relation to the toys, a contextualization that provides evidence of a social relation (Brougere, 2006). 
The metaphor of 'semiotic landscape' allows for the understanding of the societal impact on visual communication (Kress and van Leeuwen, 1996). The term, taken from the theory of social semiotics, provides a means of: "understanding the context of the range of modes in public communication within a specific society and, on the other hand, their uses and valuation' (Kress and van Leeuwen 1996: 35). The landscape of each museum varies, just as a landscape in nature changes with the seasons, time, and light. To understand the context of a specific exhibit it is necessary to take into account the environment surrounding it, its history, its development, and the juxtaposition of the objects within the exhibit. A curator's choice of modes for representation becomes a central issue, and answering these questions provides the opportunity to assess if or to what extent children's perspectives are considered within toy museums.

Based on this approach, our primary objective was to better understand the curatorial considerations involved in exhibiting toys to determine if children's perspectives are considered in the chosen method of representation. Based on our research interest, the scope of the research does not include guests' interpretations or other child-oriented museums (i.e., museums of childhood or children's museums), as it was designed as a small parallel PhD study. As academics in Denmark (one American, one Swede), our museum choices were selected in Scandinavia due to authorial familiarity with them. In addition, due to favorable and progressive social policies towards children and childcare it is possible that a Scandinavian context offers a distinct perspective.

In order to answer our questions, several areas framed this research: the Scandinavian approach to children; children as a marginalized part of society; defining the term 'toy'; toys as the tangible and intangible heritage of children; and the context (narrative \& voice) of toys in museum settings. The paper is divided into four sections: the introduction, relevant background, two case studies, and concluding comments.

\section{Scandinavian child policy approach}

Scandinavia is known for its tradition of placing family policy at the top of its agenda. Scandinavia's welfare is based on equality, equity, children's health and children's education. Sweden and Denmark in particular are considered trendsetters in regard to their perspectives on children, as their modern legislation protects children as a minority group and does so on an individual terms, not as a collective: this is distinctly Scandinavian. Both countries have high literacy rates, in part because of early childhood education promoting the value of play integrated with learning (Baumer, Ferholt, Lecusay 2005). In Scandinavia, early education focuses on the whole child and requires the school curricula to integrate play with learning; therefore, children gain independence through the social aspects of preschool, where play and learning, or narrative learning (Hakkarainen 2004), are natural parts of their daily lives (Pramiling and Carlsson 2008). Thus, Scandinavian children are given the occasion to be seen and heard early in life (Sommer, Pramling, and Hundeide 2010). This is accomplished through preschool (starting as early as age one), where children learn to express thoughts, develop their own opinions, and accept responsibility for their own actions (Sommer, et al., 2010).

Sommer, Pramling, Carlsson, Hundeide, and Hakkarainen are some of the leading figures in Scandinavia's early childhood pedagogy, suggesting that through the above method children learn to understand democratic principles by participating in decision-making where their own perspectives are taken into account, such as school and home. The only methodology used involves interaction, communication and play. Sommer et al (2010) point out the difference between child perspectives and children's perspectives: the latter refers to those of the children themselves where the former refers to those from an adult's perspective. From this it would seem more likely that in Scandinavia toys might be exhibited from a children's perspective.

\section{Marginalization of children}

Brian Shepard (1996) suggests, that, collectively, children are in their own cultural group that is often marginalized. He adds that children are seen as having no significance, unworthy, and are not seen as people with their own thoughts, ideas and opinions. History concurs with 
this and points to their difficult past, for example, the British colonial handling of Indigenous children, child trafficking, and slavery, and under-age textile workers (Darien-Smith and Pascoe 2013). Because of this, and their age, children are unable to stand up for their rights, for the preservation of their culture and are overlooked collectively as a cultural group even though that group can be broken into distinct factions (Shepard 1996; McRainey and Russick 2010). Regarding childhood and children's material culture, children's voices and perspectives should be taken into consideration (Pramling Samuelsson and Asplund Carlsson 2008; Mitchell and Reid-Walsh 2002). Even some 30 years ago, research emphasized that children's perspectives were always a matter of adults' interpretation, a concern also found by more recent researchers (c.f. Bronfenbrenner 1979; Hirschfield 2002; Brougere 2008; Darien-Smith and Pascoe 2013). Issues regarding the marginalization of children provide a parallel to indigenous communities, where the Imperial mindset (the adult in this case) is believed to surpass that of the native (the child). Other parallels center on the heterogeneity of children's histories being different and not collective, the importance of the intangible aspects of their culture, such as oral history, and cultural heritage as 'closely aligned with history' (Darien-Smith and Pascoe 2013:3).

To create a distinction between what is considered the voice of the child versus that of the adult, specific terminology is needed. Researchers (Brookshaw 2009; Darien-Smith and Pascoe 2013) corroborate this, suggesting that the material culture of children relates to toys children create for themselves and/or adapt into their culture from an adult world, and the material culture of childhood relates only to toys designed and manufactured by adults for children. These definitions are in line with the above-mentioned Scandinavian pedagogics put forth by Sommer et al (2010), which similarly emphasize the difference between child perspectives and children's perspectives. Children's perspectives and the material culture of children relate to both the tangible and intangible aspects of the object. Differentiating between the two terms not only provides specific domains for future research involving toys, learning, and socio-cultural understanding, but also provides additional means of analysis for the semiotic landscapes within toy museums.

When different narratives of childhood and toys are missing it creates the appearance of elitism and legitimizes a certain form of social practice that excludes specific members of society-pluralism is non-existent (van Leeuwen 2005). Thus, attention needs to be given to what is not represented as much as what is represented in museum exhibitions (Marstine 2006); for a toy museum this suggests the need to consider whose childhood is represented.

Research shows that visual narratives provide an effective tool for meaning making, as it is through the activity of storytelling that people are able to share their understanding of something. Museums provide such visual narratives (Hooper-Greenhill 2000). The placement of display cases and the objects inside frame such narratives and contribute to the linking of information and context (van Leeuwen, 2005). According to Tricia Austin (2012:107), the narrativity of a space determines the degree of 'storyness'; she describes the narrative process as 'laid out as a sequence' (2012:115) where the author (curator or collector) develops the story and delivers it to the audience. Also, visual cues taken from individual exhibits and from the overall semiotic landscape (Kress and van Leeuwen 1996), the scopic site (Hooper-Greenhill, 2000), or overall physical dimension (Falk and Dierking 2000) of the museum creates additional narratives. Thus, narratives are created through the placement of the chosen objects within the exhibit, the physical plan of the exhibit in relation to adjoining exhibits, and the various modes used within the exhibit. It is through the multimodal aspects of the museum, such as lighting, sound, and colors that allow specific narratives to provide additional means of creating or enhancing meaning, i.e., a bold color panel on one wall, a spotlight focused on a solitary object, the movement or sounds of objects-all draw attention to specific objects or areas of the exhibit creating salience.

Additionally, children are still rarely considered as the audience, despite new museology placing more focus on being more inclusive (Hirschfeld 2002; Sandell 2003; Roberts 2006; Townsend 2012; Darien-Smith and Pascoe 2013). Typically, children's significance in museums is through visitor studies and educational aspects rather than their involvement in the how and why of the representation of their material culture. Children are rarely involved in the planning or actual curation process, yet to be more inclusive museums need to involve those whose culture is represented-children being no exception. 
An example of how partnering with children can work was the Shhhh! It's a Secret! exhibit in 2010, where twelve young students (ages 9-11) developed and carried out an exhibition with the help of the curatorial staff at the Wallace Collection in central London (cf. Bryant 2011). Bryant proudly stated the exhibit was one of the museum's most successful to date, and that 'it was far more imaginative and subtle than the one the learning department would have developed' (Bryant 2011:398). This example seems to be outside the norm, thus a natural question follows: to what extent are children's perspectives included in (the creation of) toy museum exhibitions?

\section{Toys as playthings and cultural heritage}

Toys are interesting cultural objects which children use, yet they are primarily developed and manufactured by adults for children. So what is a toy? The answer to this question is dependent on the person who talks about the toy. The Oxford Advanced English Dictionary $5^{\text {th }}$ edition defines a toy as: 1) an object for children to play with, 2) an object you have for enjoyment or pleasure rather than for a serious purpose (Hornby 2005:1625), which conveys the message that a toy is a means of entertainment and nothing more. From a social semiotic perspective, van Leeuwen and Caldas-Coulthard (2001:1) describe toys as resources for children:

with which they can explore the world in which they live, whether by reading them as 'texts' or by using them in manipulation, but they can also be loaded with explicit and sometimes implicit agendas by the designers of the industry, and in this sense they can form a repository of societies 'value systems' and 'ideologies'.

According to Resnick (2007), toys are essential parts of play and learning. The author argues that although children use different objects and material for play, they imagine, share ideas, and reflect on their experiences by means of these resources. Based on this, we could state that toys are produced for play and playful activities, but still many definitions of toys address their uselessness, and that they bring temporary happiness to the player that is easily replaced by something new (Sutton-Smith 1997; Heljakka 2013). In a toy museum children most often cannot play with the displayed toys, but merely read them as texts, (van Leeuwen and CaldasCoulthard, 2001).

Play is nevertheless of central importance in considering toys as children's playthings. In the toy museums visited, there was no sign of 'childish' playful activities, but then 'toys' connoted a different meaning for each curator as well, e.g., as collected toys or preserved nostalgic objects. In both cases this resulted in exhibits that were specifically intended for an adult audience as a walk down memory lane.

Toys are considered as the 'archetypal symbols of childhood' (Darien-Smith and Pascoe 2013:7), wherein historians and archaeologists turn to children's material culture to fill in for the 'lack of children authored sources of the past' (Henrich 2014:134). However, the representation of toys as historical objects is no different than that of other objects displayed in museums, which promote what Kirsehnblatt-Gimblett calls the two hallmarks of display, 1) the 'foreignness of the objects to the their context in the display' and 2) 'the location of meaning at their destination' (1998:1). Context is essential to the representation of objects and provides opportunities as well as constraints on what meaning is represented through them (Kress and van Leeuwen 1996). A teddy bear, with no personal narrative, is a static artifact on display: it conveys little history other than a date and the manufacturer; it is a foreign entity where 'meaning becomes detached and contextualized' (Kress and van Leeuwen 1996: 3).

The natural environment for a toy would be the one created by the child through imaginative play and relates to intangible heritage aspects of children's toys. Henrich (2014) illustrates the above point with a teddy bear with, while a toy at a holocaust museum provides a different meaning. An exhibit in 2015 at the Israeli Yad Vashem Museum, Jerusalem on the Holocaust used children's toys, diaries, and poems to tell the horrific stories of what the children lived through at that point in history. As an example, a woman now in her 80 s provided narratives of how she and her teddy bear communicated together and how its company kept her family safe while giving them hope in an otherwise desperate time ${ }^{2}$. The combined knowledge of the woman's history with the bear provides an intangible aspect of the personal meaning 
attached to the teddy bear versus its otherwise static role as artifact. What this intangible aspect demonstrates is the ability of toys to carry complex significations as exceptionally meaningful cultural objects (Brougere 2006) where personal narratives mediate and enrich the physicality of the toy.

The cultural significance of mass produced toys tends to override the value and importance of home made toys, which leads to a dearth of the latter in museums (Brookshaw 2009). Perhaps this is because homemade toys do not necessarily make worthy visual objects in exhibits, as much of their construction is formulated in the child's imagination. However, often these toys provide the most playful curiosity, fun, and learning for small children. UNESCO developed five domains of intangible heritage $;^{3}$ four of them cover playful experiences related to toys (Davey, Darien-Smith, and Pascoe 2013):

1) Oral traditions such as rhymes, nicknames, songs, chants;

2) Performing Arts like skipping rope, string games, pantomime, clapping games, hop-scotch;

3) Traditional Craftsmen or self constructed toys and play settings developed from a variety of materials and imagination; and

4) Social practices like role-playing, the inbetweeness of play that happens between going to and from school, and other games.

Typically, these items are missing from representations of childhood, yet are very much a part of it. For a curator, the intangible aspects add to the complexity of representing a child's creation of objects as playthings versus a physical cultural object.

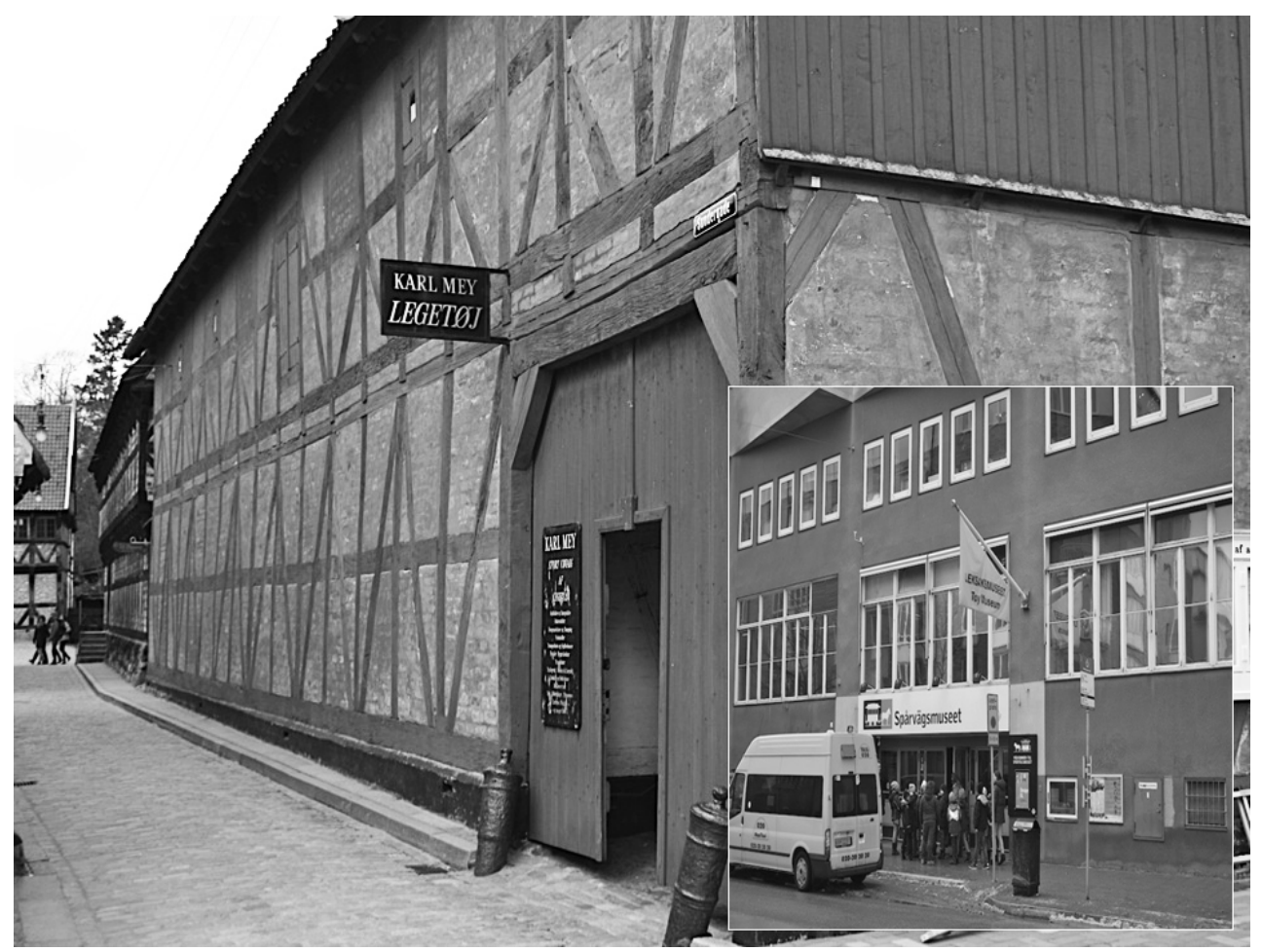

Fig. 1 and 2: Exterior of both museums 


\section{Two countries, two landscapes, two discourses}

To explore how children's voices and perspectives are included in toy museum exhibitions we carried out in-depth interviews with the lead curator of two toy museums (Figs. 1 and 2): Den Gamle By (The Old City) in Arhus, Denmark and Leksaksmuseet (The Toy Museum) in Stockholm, Sweden. The participants in the study are not intended to be representative of a larger context of curators. Rather, the purpose of this study was to achieve an in-depth understanding of the conditions and concerns surrounding curators when developing a museum exhibition where marginalized groups are represented. Through this examination, we attempted to identify the beliefs and intentions that inform both the museum and curator. Accordingly, the method was qualitative and intended to capture communication in several sign systems and therefore, beside in-depth interviews, the research included photography as image-based data and observation/mapping of the exhibition layout.

The 'semiotic landscape' is the overall driver for the analysis. Placing this in a museological context includes the objects curators chose to present and the specific viewpoint chosen to represent them; in other words, a specific context. It is a choice that arises from the socio-cultural history of the museum as well as of the curator and the existing knowledge of the objects' narrative. Thus, the same object in different contexts and hands will provide a uniquely different narrative.

For this analysis we have used the concepts of framing and linking (van Leeuwen, 2005) in order to identify and understand what kind of narratives that are communicated through the exhibited objects. Framing creates a sense of disconnection or connection between the elements in an exhibition, for example through empty spaces between exhibition cases. Linking refers to how items of information are linked to each other and how the exhibited objects are linked to their context, which additionally includes the curator's interests and purposes (van Leeuwen, 2005).

When it comes to the understanding of the playful aspects of the narratives, we have applied two of UNESCO's domains of intangible heritage, namely self constructed toys and play settings developed from a variety of materials and imagination, and social practices, in particular focusing on the in-betweenness of play, i.e. the play that can emerge in between or related to different activities.

\section{Historical narratives of childhood}

Den Gamle By opened in 1909 as the world's first open air museum, and is made up of 75 historic buildings from Denmark's past ${ }^{4}$. It is one of the country's top attractions (it has received three Michelin stars), where visitors walk down cobbled streets straight out of a Hans Christian Anderson story to the toy museum housed in an old warehouse from the 1600s. A placard dedicated to the collector who donated his toy collection to the museum is on the outside of the building. According to the curator, the toy museum opened in 1996 and has remained the same ever since. The collection is made up of mostly German toys primarily from the late $1800 \mathrm{~s}$ and early 1900s, to a few from the 1960s: it consists of approximately 10,000 toys, with the majority being for boys. The interiors are framed by warm lighting, revealing old beams and wide wooden floorboards. The curator ${ }^{5}$ stated the intention was 'to give you the impression that your childhood was warm', or what the Danes call 'hyggelig'. The curator holds a degree in Archaeology and has worked at the museum for many years. The exhibits are placed on two floors with the majority of exhibits on the first floor (Fig. 3).

The toys are arranged as 'a mixture between playing with toys and as a private collector might do' 6 , and closely linked to their history and related memories. The aspect of 'play' is brought into the exhibits through the movement of certain toys, thematic sounds, and carefully considered vintage photographic black and white murals: each of these in their own right provides salient features that draw on the exhibit's theme, which add a important visual connection to an otherwise static collection. These framing and contextual aspects exhibited nevertheless represent preserved adult nostalgia rather than children's playthings. A bench was intentionally attached to each exhibit, providing both a resting place for adults and for smaller children to stand on and get a better view. The intent according to the curator was to develop interaction and narratives between parent and child, which was observed towards 
the end of our visit. This physical set up and the visual cues from the linking of different toys together with additional interpretive elements created a space, which enabled the visitors to share educational and joyful stories.

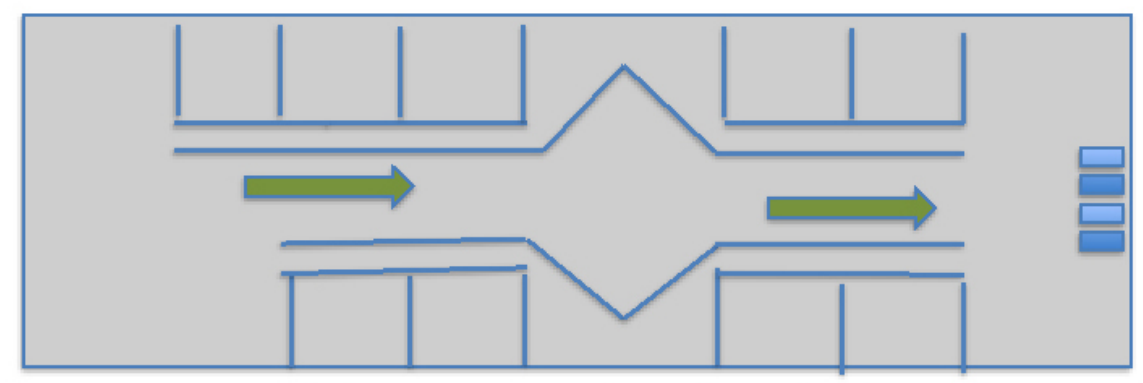

Entre/Exit - Boats- Steam Engines Mills- Music-Prison- Mech.

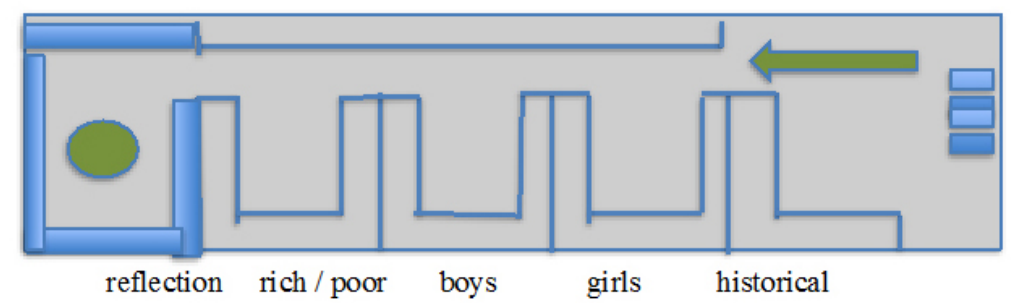

Fig. 3. Mapping of Den Gamle By. The upper diagram is the first floor and the lower the second floor.

While standing in front of the exhibit of war-related toys with the sounds of guns being fired in the background, the curator suggested that, 'this is a way for grandparents to talk about what they went through in the 1940s when the Germans were here ${ }^{77}$. Thus, it is through the various modes of the exhibit that communication can be prompted, where the sound functions as a supplement and support to the visual narrative (Kress and van Leeuwen 1996). The results from the study showed that the linking of these different modes spatially extended the toys exhibited.

When we asked the curator whom the exhibits were created for, the answer was clear:

Primarily collectors and adults, our favorite target was grandparents with small kids because kids in 1996 or 2012 don't know what this is so, most of the toys they don't recognize. They need their grandparent to tell them, 'Oh when I was young we used to play with this and this'8.

He then related a story to us concerning the musical toy exhibit (Fig. 4). A group of visiting children from a kindergarten pointed to a gramophone and said, 'WOW, WOW, there's a very old CD player!'9 The curator pointed out that this type of comment by children provides the stimulus for narratives provided by grandparents/parents/teachers that enrich the child's experience. As previously noted, such a statement promotes a socially-mediated dialogue that has the potential to build on the child's existing knowledge. Through the narrative about the turntable and the CD player, the child explores the intentions, values, knowledge that the parent built into it. This has implications for the design of exhibitions in museums, showing how some narratives and learning are enabled and others are constrained. 


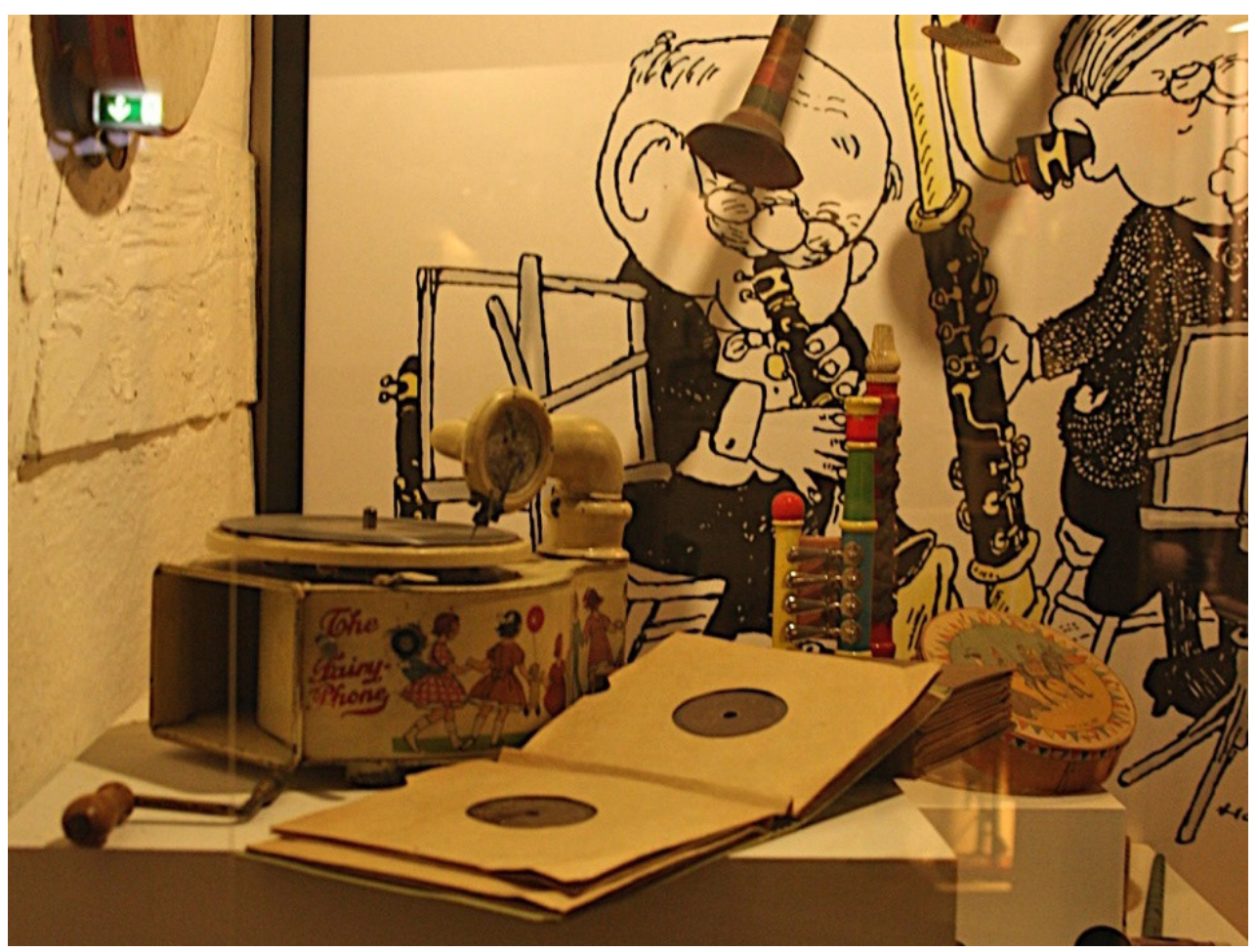

Fig. 4: 'CD’ player in music exhibit at Den Gamle By

The power of the curator is to display objects so that they can be transformed into creative and imaginary narratives for the visitors, and arrange them so that they might match the interests of the visitors. In this way, curators create conditions for the visitors to, bodily and verbally, share stories and make memories into shared conceptual systems (Nelson, 2011). So, even if the child cannot manipulate a certain toy in the exhibition, the narrative (and inherent dialogue) becomes superior to playing with the toy.

But what happens if the parents going through are too young to remember the toys on display - what becomes of the narrative? For displays that are set up as historical vignettes it at some point becomes problematic for a higher percentage of visitors to receive the intended meaning. In such cases meaning needs to come from other aspects of the exhibition's semiotic landscape, such as written and visual narratives in the form of lighting, motion and sound in the case of this museum, but also interactive images on screens where objects can come to life and tell a story, as with the exhibit on war-related toys.

The exhibition at Den Gamle By is limited in the scope as the objects are from one collector; therefore, they reflect a specific timeframe (late 1800s to mid 1900s) and his personal interests. While the lower floor is thematically exhibited, the upper floor provides gender and lifestyle exhibits. Here the vignettes provide a glimpse inside the bourgeois world of high society at the turn of the nineteenth century: it was then as it is today, a world known by only a few Danish children.

According to Ingrid Henriksen, University of Copenhagen (Economic History Association, n.d. $)^{10}$, it wasn't until the 1950s that industry overtook agriculture as the main source of the country's economy, even as seventy-five percent of the agricultural land was still farmed. Henriksen asserts that before 1914 industrial exports were approximately ten percent compared to agriculture having a sixty percent share. As of 2011 , farming was still more than fifty percent of the country's land use. Knowing this, one needs to question why the exhibits place so much focus on worlds that clearly did not exist for the Danish majority. It seems to beckon to the urban 
educated high society having more knowledge and importance-a superior one-upmanship. It also reflects the wealth and interest of the collector whose collection the museum had to work with. How interesting a contrasting exhibit would be reflecting the childhood of country life juxtaposed with that of the urban. However, this example is not alone in presenting exhibits of class distinction. Lynette Townsend (2012) refers to the same type of elitist representation in research on the representation of children at two museums in New Zealand.

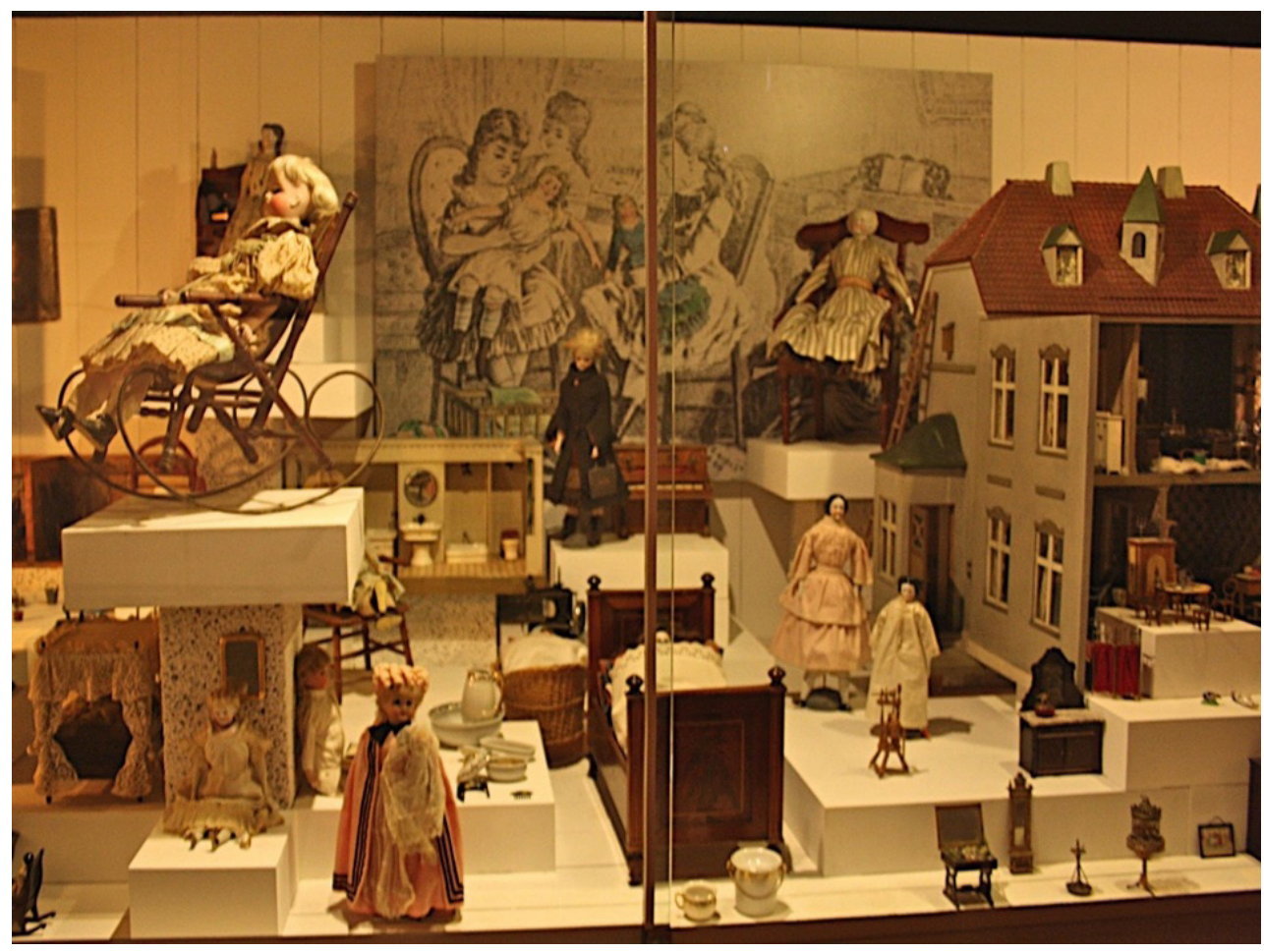

Fig. 5: Girls exhibit (upper level) Den Gamle By

At Den Gamle By the 'girls' exhibit showed dolls, furnished doll houses, children's dish sets, sewing machines, and other gender appropriate toys reflecting how girls should emulate the role of their mothers in the demands of the home: an approach that recalls the ideology of the early part of the twentieth century (Fig. 5). The curator commented:

This one, without words, shows what we wanted our girls to do when they grow up like (pause) what they wanted their girls to do when they grow up. Anything at all you see here; are you cleaning house, are your nursing the kids . . . I just love the small items, real pictures ... If you've ever wondered what a family in 1848 , I think, lived you can see it here (he points to a doll house). ${ }^{11}$

Thus, as with the majority of toys in the museum, the girl's toys also reflected those found in affluent households. Although informative from a historical view, such displays provide little to show changes or encourage change in the divide between classes or role distinctions between genders. The curator seemed aware of this as he mentioned that many of the tin toys on the first floor would equal the average working man's monthly pay in the 1940s. This provides an example where additional text or other formats could add a much needed comparison and/or prompt discussion about such divisive current issues.

To some extent the historical and bourgeois focus reflects the collector; however, the overall museum theme is to provide a sense of Denmark's history. To that extent it would benefit 
the museum to engage the public in collecting children's material culture and working more with other source communities, i.e., small towns; farming and island communities, and immigrant communities. ${ }^{12}$ The exhibit provides a window on a small fragment of a Eurocentric society while failing to introduce the 'other' (Shepard, 1996). As a living museum, one can walk from the toy museum down a small alley and see a blacksmith or butcher at work, so the museum is providing a view of 'other'- it is just that this provision is limited within the toy museum.

The boys' exhibit also represents an affluent boys' traditional role in society, with objects including a circus set from the United States and a French orangeri. In the corner sitting up quite high is a castle with toy soldiers around its perimeter, while lower down is a large barn complete with a menagerie of farm animals and tractors. Whether the positioning of the two has any subtle significance is anyone's guess; moreover, we tend to assume it was because of the difference in size than because the barn was lower than the house of royalty.

Acting as a counterpoint to these two exhibits is a one small display in a side area off the main corridor with simple stone toys from Denmark's prehistory and handmade toys and wooden toys, 'for the rest of the population'. ${ }^{13}$ If the curator had not been with us, I am not sure we would have noticed or known about the prehistoric toys as there was no form of narrative present. With the wealth of prehistory finds in Denmark in general, the basis of Den Gamle By as a historical museum, and the fact the curator was an archaeologist it is surprising no narratives were present.

The last exhibit returned to the 'toys wealthy child would play with on a Sunday afternoon, mostly educational toys' ${ }^{14}$ This illustrates the thematic nature of the display versus focusing on the actual history of individual children that leads to an unbalanced presentation of gender, wealth, and personal history (Shepard 1996).

The above-mentioned examples suggest that the semiotic landscape of Den Gamle By represents a material culture of childhood from selected narratives rather than a variety or, in the terms of van Leeuwen (2005:256), a social unison where the toys exhibited 'sing or play the same notes'. In this way, the curator exposed a monophonic ensemble of voices rather than a multi-voiced culture of childhood or children. This way of acknowledging only some narratives and excluding others links the various toys by their similarity rather than by contrasting, and pursues a biased bourgeois history.

However, the curator commented the exhibit was dated and that the toys were static. If financial resources were available, he would like to incorporate video screens that could show the 3D movement of the toys and additional information. Currently there are folders next to each display with the objects listed and dated in Danish; however the exhibits have brief descriptions for each exhibit presented in Danish, German, and English: he would also like the object lists in all three languages. He would like to remove many of the wooden boxes that provide different levels for the toys with ones that are clear. Mostly he would like to improve the lighting in order to focus in on specific toys. While these are all good initiatives there are at least two barriers, 1) money, which is problematic for most museums; and 2) the museum management needs to share the curators' vision: in this case, the manager's concerns were 'clean toilets, good coffee, and having something nice to look at'. ${ }^{15}$ The curator noted there are differences of opinions on what should be taken as priorities.

\section{Playful 'storyness'}

The Leksaksmuseet is situated within another museum, the Spårvägsmuseet (Tram museum), a short distance from Stockholm's center. ${ }^{16}$ The building is an old tram warehouse (Fig. 2) where the ceilings are 7-meters high, and supported by huge conical columns. To enter the toy museum the visitor takes a short journey through a portion of the tram museum, past an open cafeteria, and then a small children's play area. The museum itself encompasses approximately 700 square meters on one floor, which despite its size is still 'too small' according to the curator, who is also a toy auctioneer and collector. ${ }^{17}$ Consideration of the curators' background provides an insight into how the museum exhibits were arranged.

Toys in the museum range from the 1800 s to the present. The exhibition consists of collections from numerous collectors who specified that their collections should stay together as one unit and not be mixed with other collections. The curator stated that this creates 
restrictions, and that 'most of the collectors providing toys are men', hence, 'more space for boy toys' ${ }^{18}$ This provides the museum guests with repetition among the exhibits, as seen in figure 6 , where the blue area designates the boys' area and yellow provides a space for toys for both genders.

This method of exhibiting is in line with the long cultural tradition of displaying toys (Heljakka, 2013); for example, children playing with toy soldiers and other kinds of figures often spend time arranging them (Hellendoorn and Harinck, 1999). Thus, it is no surprise that toy collectors find it personally rewarding to display their collections by their size, color, manufacturer, or aesthetics (Heljakka, 2013). Although both museums were 'collectors collections', the Leksaksmuseet exhibition offered a markedly different semiotic landscape and socio-cultural interpretation of toys.

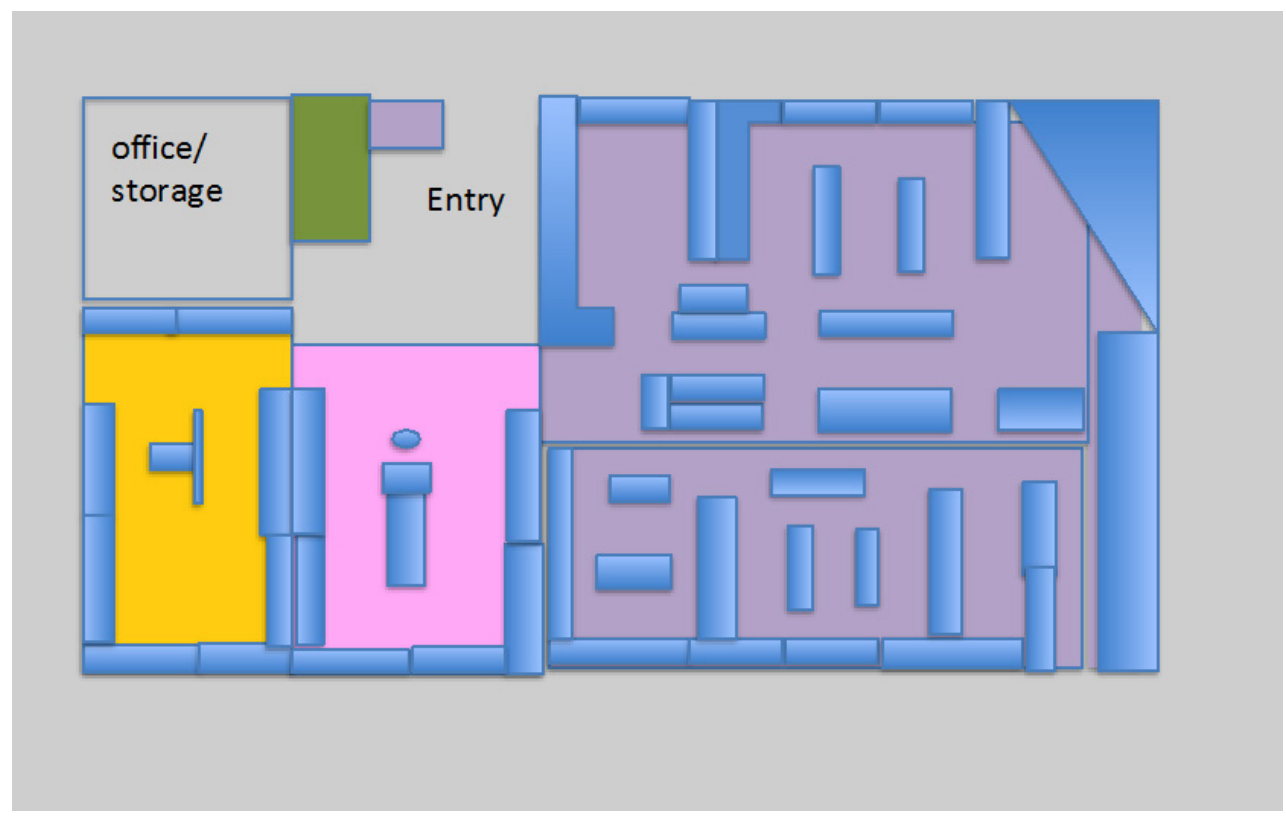

Fig. 6. Mapping of Leksaksmuseet. Blue area is the 'boys' area' while the pink is the 'girls'area'.

An overwhelming part of the landscape difference was reflected in the exhibition cases (Fig. 6 ), which were a conglomeration of 'gifts from other museums, the very big cabinets are from north Stockholm that held animals and they are very old fashioned'. ${ }^{19}$ The pink area in figure 6 designates the limited space for girls toys (primarily dolls, Barbie and family, foreign dolls, and doll houses); there was one exhibit case in the shape of a house painted a pale pastel shade, although the curator mentioned he had more of these, none were in use. Janet Marstine (2006) suggests that framing controls the viewing process by setting contextual boundaries that influence our understanding of what is included. However, in the haphazard methodology of object placement this exhibit did not communicate any difference from one display to the next. At the same time, this chaotic and seemingly unsystematic way of exhibiting toys at the Leksaksmuseet created relevance for the visitors and invited them to acknowledge the objects as something it was possible to do something with, rather than just being static items.

While observations were not on our agenda, we unwittingly visited the Stockholm museum during a school break, making it difficult not to make some observations of relevance. There were several groups of young children (approximately four to eight years old) visiting with their caretakers or parents. Some of the children ran around to several of the exhibits-seemingly knowing where to go to seek out the 'active' parts of the exhibit. According to R.F. Law, in The Representation of Childhood in Museums, museums view such 'school groups' as passive 
participants coming to the museum on school visits or on holidays, and relate to them more as a commodity for the pedagogical and didactical concerns relevant to the museums to be seen as educational institutes (cited in Roberts 2006:155). Emphasis is placed on the word 'passive' as it implies that children play a non-active role when the exhibition is planned or in the overall learning that might take place (Shepard, 1996).

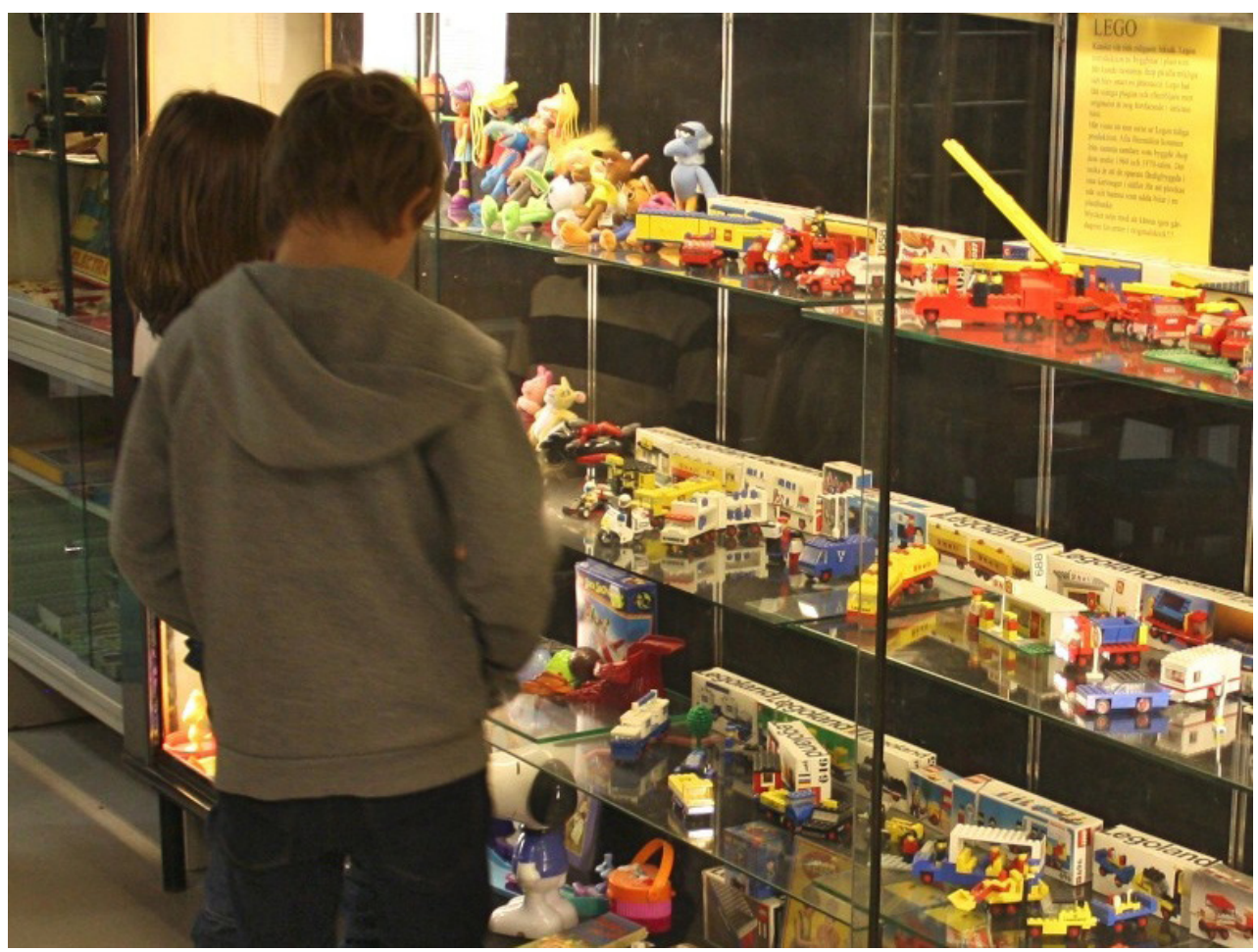

Fig. 7: Children in dialogue with one another about the LEGO display at Leksaksmuseet.

Additionally, the children observed were more concerned with the objects themselves rather than with the chaotic manner in which they were exhibited. Two young boys were darting from one exhibit to another before settling down in front of the LEGO exhibit where they pointed to the exhibit and then chatted with one another (Fig. 7). It appeared that they were very physically engaged in gesturing while creating and sharing narratives about the toys in front of them. In the words of Daniel Spock (2010:121) 'children find their experiences more memorable and positive when they are fully engaged in active, imaginative thinking'. From what we could observe, these young boys were immersed in their own experiences with LEGOs, which were recalled by the display. This can be understood as mediation between the object and the child where the toy moves from being an ethnographic object in a museum to that of an agent that initiates dialogues between two people looking at it. Children have the ability to play, in this case, to view the toy as a social product from their own culture. In other words, the chaos seemingly encouraged the children to learn and internalize social and cultural practices (Petersson, 2006).

This is to say that they do not play directly with what adult society produces (Brougere 2006); instead, they make their own interpretations, adding to the complexity of the social process. At this level the child becomes a co-producer with adults in the world of significations through their playful activity; a very Scandinavian concept of play activity (Sommer et. al. 2010). Although play and narratives are not the same, Sutton-Smith (1997: 171) points to a connection through children's 'phantasmagorical play', which is a kind of imaginary play 
based on ingredients in children's narratives and daydreams, offering children opportunities to (re-)articulate their own cultural interpretations and fantasies through framings and their own mutual negotiations. In this sense, the children we observed created connections between play and narratives, which were embedded in social practices and situations determined by the participating children's imagination, influencing the nature and pattern of interaction with the exhibit by sharing their understandings and experiences with the toys exhibited and with toys in general. The exhibit represented a social practice that was closely linked to the childrens' lifeworlds and perceptions of their own history and memory and the children created their own play space where they passed on their experiences to each other. ${ }^{20}$

While Leksaksmuseet did not have a defined educational agenda, most of the children stayed as groups moving with their caretaker through the exhibit. Our observations showed that it was only when pairs of children broke away from the group that their interest and activity seemingly heightened. This is backed up by research that suggests that such a reaction is the norm. Falk and Dierking (2000) refer to research done by Janette Griffin, who found that children prefer to go to museums with their family so they can choose their own interests, instead of with school groups where their interests are constrained and decided for them.

Even though we observed much activity from the children, the curator suggested he would like to integrate more opportunities for children to be active. The curator suggested he would like the addition of playful physical elements in between or under displays that children could move through:

It's enough with a big barrow and it can be between some cabinets and you can go in and out, or put something in a corner. It's enough with a house that you can look through a window, you could paint it red or blue or yellow. ${ }^{21}$

Furthermore, he emphasized that different kinds of narrative and play spaces were needed in order to open up areas for children and parents to share activities: 'In that little space we have storybooks so parents can read to the children /.../ And also, this museum has a very big space and has room for children to play.' In this way, the curator had the intention to, through creating place and space, ensure that this specific cultural heritage was passed on between generations, providing reflective and playful forms of 'storyness'.

However, good intentions do not equate to having the finances, space to implement the ideas, or the management in alignment. The curator stated that although the chairman of the board was an 'enthusiastic eighty-four year old that would like to continue as chairman for another 'seventy-five years'!22 that this same chairman felt 'no resources were available', counter to what the curator and most of the museums' board believed. The curator thought 'younger members should be brought into the board'-something he pointed to as 'not being all that easy to accomplish'.

Younger members can create change, as Townsend (2012) discovered in her work at Te Papa in New Zealand. She found that young curators who have museology training are more likely to embrace the concepts of new museology. One young history curator specifically sought children's cultural objects that suggested more social influence than her predecessors, i.e., paper dolls and other objects of everyday life. Other forms of change could be accomplished with inexpensive changes such as a coat of colorful paint on the exhibition wall or cases, or a focal point at the entrance that provides a visual element shouting 'childhood' without additional narratives. Such was the case at the Kid Size: Great Toys from Our Childhood exhibition organized by the Berkshire Museum in Pittsfield, Massachusetts where the exhibit entry portals and room dividers implemented the use of primary colors and simple geometric forms associated with childhood (Van Slyck, 2004). In writing about the exhibit, Van Slyck suggests the oversize shapes provided adults with a reminder of feeling small and childlike.

Leksaksmuseet was shaped by aesthetics where the affordances should satisfy both collectors' and children's requirements and needs. This was accomplished mainly through the linking of different collections in order to produce a politically correct and playful aesthetic. The main emphasis was on the fact that the different toy collections should be kept together and that children and adults should navigate through the exhibition driven by remembering and curiosity, where play was represented through an unstructured layout and the inclusion of modern days toys. There was no inclination of the bourgeois attitude of Den Gamle By seen 
here; instead toys were shown as simple as they were given to the museum-worn, torn, or ready to go to a collectors show. The curator expressed his attitude as:

I am most interested in old toys, homemade unique toys, a cultural part of the Swedish childhood. You cannot buy them. I can always buy an expensive doll to collect, but those toys that are cheap, or that a child made herself are more valuable. $^{23}$

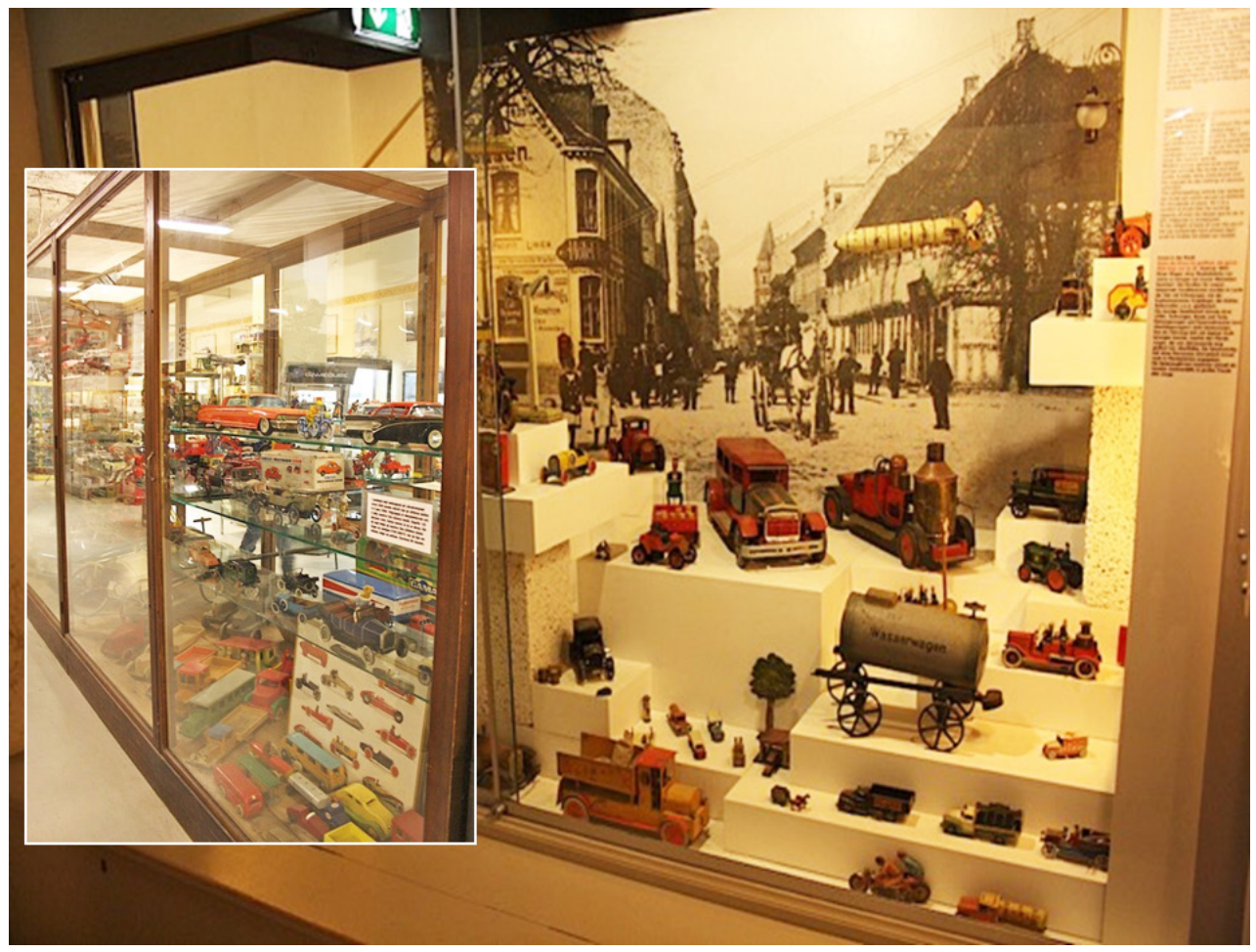

Figure 8 Car exhibits Den Gamle By in background, Figure 9. Leksaksmuseet in inset.

\section{Vroom, vroom: contrasting car exhibits}

No matter what variety of toys we selected for comparison the differences would be substantial just due to the physical constraints of the exhibit spaces and their overall contexts. For example, we examined both museums' methods of representing cars. In Den Gamle By the car exhibit (Fig. 8) presents a graphic backdrop of a nearby city showing a cobbled stone street with a horse and buggy from around the early 1900s providing a salient feature as well as a historical timeframe for the exhibit. Historical continuity is kept with the age of the toys displayed, and central in the exhibit was a toy horse and buggy offering a connection back to the graphic.

The cars and other transportation vehicles are positioned on different size cubes of varying heights creating small vignettes incorporating gas lamps and gas pumps from the era. This multimodal method of developing the display allows visitors to focus on more details; therefore, providing more opportunity for narratives between parent and child. When dirigibles flying overhead come to life with a whirring sound above the exhibit, the sounds create a playful sensory cue enhancing the overall experience.

In the Leksaksmuseet there were numerous exhibits with cars; according to the curator this is due to cars being a favorite item of the collectors who donate their collections to the museum. A car exhibit centrally located in a large cabinet provides a good comparison of just 
how many objects are in the Leksaksmuseet collection (Fig. 7). Unlike Den Gamle By, cars and other transportation vehicles are placed on glass shelves with the largest wooden vehicles on the bottom. There is no specific timeframe for the objects as they are from different periods during the 1900s.

Since essentially collectors designed their own exhibits, several of the cars have the original boxes with them, signifying added value for the collectors and salience for the viewer. At the same time they provide a semiotic resource as the 'graphics' and 'text' can help spark childhood memories for the older museums guests. The Leksaksmuseet curator commented on the opportunity for engagement and dialogue between parent and child when adults would recognize a car from their past. Thus, the car became a mediator for further conversation on cars, their childhood, or play. Through such mediation the car stimulates memory for the adult and learning for the child (cf. Wertsch 1993). On this same idea, Miller (2008) states that a visual display includes a potential story or an externalized memory.

\section{Concluding comments}

We have investigated how two Scandinavian toy museums represent the material culture of children. Through our interviews with lead curators and the concept of 'semiotic landscape' (Kress and van Leeuwen, 1996) we were able to answer our initial questions concerning intended audience, who was involved in the exhibition development, and whether the narratives provided a voice of children or of childhood. What we found were two very distinct semiotic landscapes: one historical and the other a hodge-podge of various collectors' collections. These different semiotic arrangements were grounded in the curators' personal, social, and institutional considerations and choices, which resulted in the two different strategies of display applied to children's cultural objects.

The semiotic resources used by both museums suggested the toy as an ethnographic object that was able to represent both the material culture of children (Leksaksmueet) and of childhood (Den Gamle By). For the latter, we initially perceived that its historical context provided more possibilities for playful meaning making through its well-defined visual themes, backgrounds, active objects, and sounds that provided implicit narratives. In hindsight, both museums provided this opportunity. Leksaksmuseet through its maze of exhibit cabinets and disarray of colorful objects, essentially created an environment and landscape for children to discover and inhabit as their own. Kress and van Leeuwen (2001) refer to this kind of dynamic and unstructured landscape as a known and natural environment for children. At Den Gamle By, the few guests we saw had very young children who were carried by their parents; in this instance the adults prompted narratives. This provided a different form of narrative stimulus than the 'WOW, it's a CD' story told by the curator. Either way, the interactive mediation between object and viewer created a sensory engagement that allowed for playful interaction and imagination. It provides a reminder that each of us, whether curator, collector, guest, or researcher will have their own toy-related memories that induce social and affective responses.

The historical, and to a great extent bourgeois, emphasis at Den Gamle By was visually appealing, but lacked relevance to the childhood of most Danish children in the early 1900s. Only a few vignettes provided any sense of average children's toys. The addition of textual narratives could have communicated such distinctions and mentioned the roles children had growing up on farms, or in small villages as being equally important as the roles of children from wealthy families.

Possible solutions could include affording a venue for pensioners and others to provide such narratives to the museum, which would support community involvement and be an inexpensive resource to update the exhibit while adding value to the collection. A similar method has been used at The National Museum of Australia's First Australians galleries, where the curatorial team have placed subtle signage within the gallery and the museums website asking for help to identify objects. This has been a very successful partnership with the source communities so personal narratives can be attached to objects and misinformation corrected. ${ }^{24}$

To some extent, the overall design layout of the Leksaksmuseet allowed children to move around freely while its carefree manner of exhibiting provided visual stimulus. This enabled children to make sense of the exhibits and play without adult direction. This is in 
agreement with the statement by Smith and Pascoe (2012:4) that children are 'active agents on their own' and is in line with current Scandinavian early childhood pedagogy (Hakarainen, 2004; Pramling and Carlsson, 2008; Sommer, et al., 2010).

From a child's perspective toys simply signify play (Pramling and Carlsson, 2008). What the two semiotic landscapes illustrate is even when toys have been decontextualized and re-contextualized as objects of childhood for collectors and curators alike, toy museums do have the capacity to include children's perspectives in the exhibition. The focus was primarily on childhood as opposed to children's perspectives at both locations, due to the adults who constructed the exhibits and the caretakers / parents who took children to the museum.

Mr Rogers was correct-there are no boundaries for children's play as they can find 'play' in places and ways that we as adults cannot.

Received 18 August 2014

Finally Approved 14 June 2016

\section{Notes}

1 Fred Rogers, Strong National Museum of Play. http://www.museumofplay.org/education/ education-and-play-resources/play-quotes accessed 21 July 2014.

2 Paul Goldman, 'Holocaust Remembrance Day: Museum Showcases Survivors' Toys', NBC news online http://www.nbcnews.com/news/world/holocaust-museum-exhibitshowcases-child-survivors-victims-n341896, accessed 17 April 2015.

UNESCO (2003) 'Convention for the Safeguarding of the Intangible Cultural Heritage'. http://unesdoc.unesco.org/images/0013/001325/132540e.pdf., accessed 9 December 2015.

Den Gamle By, Århus, Denmark. http://www.dengamleby.dk/the-old-town/, accessed 21 July 2014.

Jan Ingvordsen, interview by authors, digital recording, 29 March 2012, Den Gamle By, Arhus, Denmark.

Henriksen, Ingrid (n.d.) 'Economic History of Denmark', Economic History Association, http://eh.net/?s=Ingrid+Henriksen, last accessed 15 April 2015.

Jan Ingvordsen, interview, 29 March 2012.

12 Denmark consists of 406 islands, 70 of which are inhabited. Jutland, where the museum lies, is a peninsula connecting the country to continental Europe. Copenhagen is on the island of Zealand in the east of the country, while the city of Odense (home of Hans Christian Andersen) is on the island of Fyn linked to Jutland and Zealand by bridges.

13-15 Jan Ingvordsen, interview, 29 March 2012.

16 Leksaksmuseet, Stockholm, Sweden, http://www.leksaksmuseet.se/html/english.htm, accessed 21 July 2014.

17-19 Mike Makusu, interview by authors, digital recording, 28 February 2012, Leksaksmueet, Stockholm, Sweden.

UNESCO (2003) 'Convention for the Safeguarding of the Intangible Cultural Heritage'. http://unesdoc.unesco.org/images/0013/001325/132540e.pdf. accessed 9 December 2015. ${ }^{21-22}$ Mike Makusu, interview by authors, digital recording, 28 February 2012, Leksaksmueet, Stockholm, Sweden. interview with Anne J. Cole (author), digital recording, 19 April 2012, National Museum of Australia, Canberra, Australia. 


\section{References}

Austin, T. (2012) 'Scales of narrativity', in MacLeod, S.; Hanks, L.H.; and Hale, J. (eds.) Museum Making: Narratives, Architecture, Exhibitions, 107-118, Oxon: Routledge.

Baumer, S., Ferholt, B., Lecusay, R. (2005) 'Promoting narrative competences through adult-child joint pretense: Lessons from the Scandinavian educational practice of playworld', Cognitive Development, 20, 576-90.

Bronfenbrenner, U. (1979) The Ecology of Human Development: Experiments by Nature and Design, Cambridge, MA: Harvard University Press.

Brookshaw, S. (2009) 'The Material Culture of Children and Childhood: Understanding Childhood Objects in the Museum Context', Journal of Material Culture, 14 (3), 36583.

Brougère, G. (2006) 'Toy Houses: A Socio-Anthropological Approach to Analysing Objects', Visual Communication, 5 (1), 5-24.

Bryant, E. (2011) 'A Museum Gives Power to Children', Curator, 54 (4), 389-98.

Darien-Smith, K. and Pascoe, C. (2013) 'Children, childhood and cultural heritage-mapping the field' in Darien-Smith, K. and Pascoe, C (eds.) Children, Childhood and Cultural Heritage, 1-17, Oxon: Routledge.

Davey, G.B., Darien-Smith, K., and Pascoe, C. (2013) 'Playlore as cultural heritage: Traditions and change in Australian children's play' in Darien-Smith, K. and Pascoe, C (eds.) Children, Childhood and Cultural Heritage, 40-53, Oxon: Routledge.

Falk J.H. and Dierking, L.D. (2000) Learning from Museums: A Visitor Experiences and the Making of Meaning, Walnut Creek, CA.: Alta Mira.

Hakkarainen, P. (2004) 'Narrative learning in the fifth dimension', Outlines: Critical Social Studies, 6 (1), 5-20.

Heljakka, K. (2013) 'Principles of Adult Play(fulness) in Contemporary Toy Cultures. From Wow to Flow to Glow', Doctoral dissertation, Aalto University, School for Arts, Design and Architecture, Helsinki: Aalto ARTS Books.

Hellendoorn, J. and Harinck, F. (1999) 'War Toy Play as a Reflection of Family Culture', in Berg, L.-E., Nelson, A. and Svensson, K. (eds) Toys in educational and socio-cultural context. Toy research in the late twentieth century, 245-261, Selection of papers presented at the International Toy Research Conference, Halmstad University, Sweden.

Henrick, E. (2014) 'Children's Toys and Memories of Migration in Australian Museums' in Childhood in the Past: An International Journal, 7 (2), 133-146.

Hirschfeld, L.A. (2002) 'Why Don't Anthropologists Like Children?', American Anthropologist, New Series, 104 (2), 611-627.

Hooper-Greenhill, E. (2000) Museums and the Interpretation of Visual Culture, London and New York: Routledge.

Hornby, A.S. (2005) Oxford English Dictionary $5^{\text {th }}$ edition, Oxford University Press: Oxford.

Kirshenblatt-Gimblatt, B. (1998) Destination Culture: Tourism, Museums, and Heritage, Berkley \& LA: University of California Press. 
Kress, G. (2010) Multimodality: Asocial semiotic approach to contemporary communication, Oxon: Routledge.

Kress, G. and van Leeuwen, T. (1996) Reading Images: The Grammar of Visual Design, London: Routledge.

Kress, G. and van Leeuwen, T. (2001) Multimodal Discourse: The modes and media of contemporary communication, London: Hodder Education.

Marstine, J. (ed) (2006) New Museum Theory and Practice: An Introduction, Oxford: Blackwell Publishing.

McRainey, D.L. and Russick, J. (eds) (2010) Connecting Kids to History with Museum Exhibitions, Walnut Creek, CA.: Left Coast Press.

Miller, D. (2008) The Comfort of Things, Cambridge: Polity Press.

Mitchell, C. and Reid-Walsh, J. (2002) Researching Children's Popular Culture. The Cultural Spaces of Childhood, London: Routledge.

Nelson, A. (2011) 'Gendered Toy Play as Mediated Action', Psychological Science and Education, 2, 71-77.

Petersson, E. (2006) 'Non-formal Learning through Ludic Engagement within Interactive Environments', Doctoral dissertation, Malmö University, School of Teacher Education, Studies in Educational Sciences.

Pramling I.S. and Carlsson, M.A. (2008) 'The Playing Learning Child: Towards a Pedagogy of Early Childhood', Scandinavian Journal of Educational Research, 52 (6) 623-641.

Resnick, M. (2007) 'All I Really Need to Know (About Creative Thinking) I Learned (By Studying How Children Learn) in Kindergarten' Creativity and Cognition Conference 2007 http://boomtreecreative.com/pdf/CC2007-handout.pdf.

Roberts, S. (2006) 'Minor Concerns: Representations of Children in British Museums', Museums and Society, 4 (3) 152-65.

Sandell, R. (2003) 'Social Inclusion, the museum and the dynamics of sectorial change' in Museums and Society, 1(1), 45-62.

Shepard, B.W. (1996) 'Making Children's Histories' in Kavanagh, G. (ed.) Making Histories in Museums, 258-269, London: Leicester University Press.

Sommer, D., Pramling S.I. and Hundeide, K. (2010). Child Perspectives and Children's Perspectives in Theory and Practice, 1-23, London \& New York: Springer.

Spock, D. (2010) 'Imagination - A Child's Gateway to Engagement', in McRainey, D.L. and Russick, J. (eds) Connecting Kids to History with Museum Exhibitions, 117-136, Walnut Creek, CA.: Left Coast Press.

Sutton-Smith, B. (1997) The Ambiguity of Play, Cambridge, Massachusetts: Harvard University Press.

Townsend, L. (2012) 'Collecting kids' stuff: in search of the history of childhood in New Zealand museums' Tuhinga, 23 39-51.

Van Leeuwen, T. (2005) Introducing Social Semiotics, Oxon: Routledge. 
Van Leeuwen, T. \& Caldas-Coulthard, C.R. (2001) 'The Social Semiotics of Toys', Final Report on Part of the Toys as Communication Project, Nordic Center for Research on Toys and Educational Media (NCFL), Halmstad University, Sweden.

Van Slyck, A.A. (2004) 'KidSize: The Material World of Childhood: An exhibition review, Winterthur Portfolio, 39 (1), 69-78.

Wertsch, J.V. (1993) Voices of the Mind: A Sociocultural Approach to Mediated Action, Cambridge, MA: Harvard University Press.

*Anne Jodon Cole: Ph.D. fellow and assistant professor at the Centre for Design, Learning and Innovation, within the Department of Learning and Philosophy, Aalborg University, Denmark. Her current research is directed at curators meaning-making processes within the context of indigenous peoples in the inter-national museum context, and the connection between pluralism and social responsibility. Her focus is on learning within museums and curatorial collaboration with source communities. Additional areas of interest include Project Oriented Problem Based Learning (POPBL) and the documentation and representation of rock art. She holds a Masters degree in Intercultural Communication and Globalization from Aalborg University.

**Eva Petersson Brooks, Ph.D. and Associate Professor in Medialogy. She is co-founder and Director of Centre for Design, Learning and Innovation, Department of Architecture, Design and Media Technology, Aalborg University, Denmark. Her research interests center on technologymediated play and learning, which is conceptualized as 'playful learning designs'. In particular she is interested in investigating complexities and potentials of using contemporary digital resources for play alongside those traditionally used for children's learning and progression through play across formal, informal, and non-formal contexts. Her research makes such practices explicit and visible and identifies how specific resources shape opportunities for how children learn. 